\title{
Measuring Forecasting Performance of Vector Autoregressive and Time Series Regression Models
}

\author{
Taiwo .A .I and Olatayo T.O \\ Department of Mathematical Sciences, Olabisi Onabanjo University, \\ Ago-Iwoye, Nigeria. \\ ab.com1982@yahoo.com and Otimtoy@yahoo.com
}

\begin{abstract}
Correlation and Regression are the traditional approach of determining relationship between two or more variables. When the variables are multiple and the dependent variable is considered having an explanatory variable, then a Vector Autoregressive model is used to determine the structural relationship between the variables. If these variables are co-integrated, VAR model is not appropriate, but our focus is on the structural relationship and measuring forecast performance of a VAR and Time series regression with Lagged Explanatory Variables. Some Nigerian economic series (Government Revenue and Expenditure, Inflation Rates and Investment) data were analysed and the Root mean Square forecast Error (RMSFE) and Mean Absolute Percentage Forecast Error (MAPFE) are used as measurement criteria. The VAR model was found to be better than Time series regression with Lagged Explanatory Variables model as indicated by Meta diagnostic tools. The forecast values from the VAR model is more realistic and closely reflect the current economic reality in Nigeria indicated by the forecast evaluation tools.
\end{abstract}

Keywords: Vector Autoregressive, Time Series Regression, Meta Diagnostics, Forecast performance.

\section{INTRODUCTION}

For most of the twentieth century, especially since the great depression, most time series macroeconomists have looked upon the sharp fluctuations in the economic series as prima facie evidence of major market imperfections (Blanchard and fischer, 1990). In order to investigate the economic fluctuations, multiple time series models was developed as an alternatives to structural econometric models in economic forecasting applications. Many time series econometricians as applied multiple time series models to investigate the fluctuations and these includes for example Aaker et al (1982), Adams and Moriarty (1981), Ashley, Granger and Schmalensee (1980) and many others.

One class of multiple time series models which has received much attention recently is the class of Vector Autoregressive (VAR) models. These models constitute special case of the more general class of Vector Autoregressive Moving Average VARMA models. Although $V A R$ models have been used primarily for macro-economic models, they offer an interesting alternative to either structural econometric or univariate (e.g., Box-Jenkins ARIMA or exponential smoothing) models for problems in which simultaneous forecasts are required for a collection of related macro-economic variables. The use of $V A R$ models for economic forecasting was proposed by Sims (1980), motivated in part by questions related to the validity of the way in which economic theory is used to provide a prior justification for the inclusion of a restricted subset of variables in the "structural" specification of each dependent variable. Sims (1980) questions the use of the so called "exclusionary and identification restrictions". Such time series models have the appealing property that, in order to forecast the endogenous variables in the system, the modeller is not required to provide forecasts of exogenous explanatory variables; the explanatory variables in an econometric model are typically no less difficult to forecast than the dependent variables.

In addition, the time series models are less costly to construct and to estimate. These imply that VAR models offer a parsimonious representation for a multivariate process. In order to determine the parsimonious representation of the VAR model, we 
will compare the forecast performance of $V A R$ and Time series regression with Lagged Explanatory Variables. Since in the literature, VAR models has been discuss to have a practical forecasting applications because of the relative simplicity of their model identification and parameter estimation procedures, superior forecasting performance and this will be verified by comparing the estimates and forecast evaluations of $V A R$ and Time series regression with Lagged Explanatory Variables models.

In this paper, we will compare the vector autoregressive and Time series regression with Lagged Explanatory Variables models. We will make use of some Nigerian macro-economic series for the period of 1970 through 2008: using yearly data. The rationale for the choice of a multiple time series technique is twofold and these are structural estimation and forecasting.

\section{METHODOLOGY}

Time series Regression with Lagged Explanatory Variables Model: The time series regression model with lagged explanatory variables is defined as;

$$
y_{t}=\beta_{0}+\beta_{1} X_{t}+\beta_{2} X_{t-1}+\cdots+\beta_{k} X_{t-k}+\varepsilon_{t}
$$

Where $y_{t}$ is a $K$-dimensional vector containing observations on the dependent variable, $X$ is a $T \times K$ matrix of explanatory variables, $\beta$ is a $K$-vector of coefficients that measures the effect of the explanatory variables on the dependent variable and $\varepsilon_{t}$ is the vector of disturbances. $T$ is the number of observations and $K$ is the lag length. The methods and procedures can be found in the literatures like Reinsel and Sung (1992), Clements et al. (1997) and Lütkepohl (2005).

\section{Vector Autoregressive Model (VAR)}

A process $Y_{t}=\left(y_{1 t}, y_{2 t}, \ldots, y_{n t}\right)^{\prime}$ denote an $(n \times 1)$ vector of time series variables.

The basic $p$-lag vector autoregressive $(V A R)(p)$ model has the form

$$
\begin{aligned}
Y_{t}=C+\Pi_{1} y_{t-1} & +\Pi_{2} y_{t-2}+\cdots+\Pi_{p} y_{t-p}+\varepsilon_{t} \quad, t \\
& =1, \ldots, T
\end{aligned}
$$

Where $\Pi_{i}$ are $(n \times n)$ coefficient matrices and $\varepsilon_{t}$ is an $(n \times 1)$ unobservable zero mean white noise vector process (serially uncorrelated or independent) with time invariant covariance matrix $\Sigma$ (Sims 1980). Assuming that the $V A R$ model contains two lagged values of the endogenous variables then a bivariate $(V A R)(2)$ model equation has the form;

$$
\begin{gathered}
y_{1 t}=C_{1}+\pi_{11}^{1} y_{1 t-1}+\pi_{12}^{1} y_{2 t-1}+\pi_{11}^{2} y_{1 t-2}+\pi_{12}^{2} y_{2 t-2} \\
+\varepsilon_{1 t} \\
y_{2 t}=C_{2}+\pi_{21}^{1} y_{1 t-1}+\pi_{22}^{1} y_{2 t-1}+\pi_{21}^{2} y_{1 t-2}+\pi_{22}^{2} y_{2 t-2} \\
+\varepsilon_{2 t}
\end{gathered}
$$

In lag operator notation, the $(V A R)(p)$ is written as

$$
\begin{aligned}
& \Pi(L) Y \\
& =C+\varepsilon_{t}
\end{aligned}
$$

Where $\Pi(L)=I_{n}-\Pi_{1} L-\cdots-\Pi_{p} L^{p}$. The $(V A R)(p)$ is stable if the roots of

$\operatorname{det}\left(I_{n}-\Pi_{1} L-\cdots-\Pi_{p} L^{p}\right)$ lie outside the complex unit circle (Lutkepohl, 1999).

Data Exploration: The pattern and general behaviour of the series is examined from the time plot. The series was examined for stationarity, outliers and gaussianity. Test for stationarity will be carried out with augmented Dickey -Fuller methods. Details of the test procedures can be found in the literature which include Box and Jenkins (1976); Chatfield 1980); Rao (1994) and Pfaff (2004). The Dickey-Fuller type of test for unit root of integer type will be used in this study. As well, a co-integration test will be carried out using the Johansen cointegration test. Details of the test procedure can be found in Lutkepohl (1991); Watson (1994).

Model Diagnostics: To check for the adequacy of the estimated vector Autoregressive models, the fitted models are subjected to model diagnostics using $R^{2}$ and Vector Autoregressive lag order selection criteria will be used to chose the appropriate model order using the AIC and SBIC criteria.

The criterions are specified as

$$
\begin{aligned}
A I C & =-\frac{2 l}{T}+\frac{2 n}{T} \\
S B I C & =-\frac{2 l}{T}+\frac{n \log T}{T}
\end{aligned}
$$

Where $\quad l(\log$-likelihood $)=\frac{T}{2}\{k(1+\log 2 \pi)+$ $\log |\widehat{\Omega}|\}, \quad|\widehat{\Omega}|=\operatorname{det}\left(\frac{1}{T-P} \sum_{t} \hat{\varepsilon}_{t} \hat{\varepsilon}_{t}^{\prime}\right)$ is the determinant of the residual covariance, $P$ is the number of parameter per equation in the VAR.

The error term is expected to be independently distributed. We check this by testing for the hypothesis of white noise residuals using the 
Portmanteau and Residual Normality tests. The Portmanteau test is used to test the hypothesis for autocorrelation, that is

$$
\begin{aligned}
H_{0}: \gamma_{1}= & \cdots=\gamma_{h}=0 \text { vs } \\
& H_{1}: \gamma_{i} \neq 0 \text { for some } 1 \leq i \\
\leq & h \text { where } h>0
\end{aligned}
$$

Where $\gamma_{k}=\left(\rho_{i j}(k)\right)$ is the autocorrelation matrix of the residual series with $\rho_{i j}(k)$ the cross autocorrelation of order $k$ of the residuals series $i$ and $j$. The portmanteau test is the Q-statistic and it is denoted by,

$$
=T \sum_{k=1}^{h} \operatorname{tr}\left(\hat{\gamma}_{k}^{l} \hat{\gamma}_{0}^{-1} \hat{\gamma}_{k} \hat{\gamma}_{0}^{-1}\right)
$$

Where $\hat{\gamma}_{k}=\left(\hat{\rho}_{i j}(k)\right)$ are the estimated (residual) autocorrelations, and $\hat{\gamma}_{0}$ and contemporaneous correlations of the residuals (Lutkepohl, 1991).

While for the Time Series Regression, $R^{2}$ is used to check the adequacy of the models and DurbinWatson statistic is used to measure the serial correlation in the residual. Following Johnson and $\mathrm{Di}$ Nardo (1997), Dublin Watson statistic is computed as,

$D W$

$=\sum_{t-2}^{T}\left(\hat{\varepsilon}_{t}-\hat{\varepsilon}_{t-1}\right)^{2} / \sum_{t=1}^{T} \hat{\varepsilon}_{t}{ }^{2}$

Forecasts of $V A R$ and Time Series Regression models are computed for out-sample values. The optimal forecasts values are then evaluated using the mean squared forecast error (MSFE) defined as,

$$
\begin{aligned}
& M S F E \\
& =\frac{1}{h+1} \sum_{t=s}^{h+s}\left(\hat{X}_{t}\right. \\
& \left.-X_{t}\right)^{2}
\end{aligned}
$$

the root mean square forecast error (RMSFE) is defined as:

$$
\begin{aligned}
& \text { RMSFE } \\
& =\sqrt{\frac{1}{h+1} \sum_{t=s}^{h+s}\left(\hat{X}_{t}-X_{t}\right)^{2}}
\end{aligned}
$$

and the mean absolute percentage forecast error MAPFE is given as,
MAPFE

$=\frac{100}{h+s} \sum_{t=s}^{h+s}\left|\frac{\hat{X}_{t}-X_{t}}{\hat{X}_{t}}\right|$

where $t=s, 1+s, \ldots, h+s$ and the actual and predicted values for corresponding $t$ values are denoted by $\hat{X}_{t}$ and $X_{t}$ respectively.

The smaller the values of RMSFE and MAPFE, the better the forecasting performance of the

model.

\section{RESULTS AND DISCUSSIONS}

The examination of the time plot (Figure 1) of the Nigerian macroeconomic series shows that there is some kind of non-stationarity and possibly nonlinearity in the observed data. It is evidence from the time plot that government revenue, government expenditure and investment show a long-term movement in the same direction over the period considered and this shown they are related. But it should be of notice the sharp fall in government revenue in 2001 and this is due to fall in crude oil price in the world market and this lead to budget deficit and increase in price of petroleum product in Nigeria. This sharp fall is referred to as a shift. Only inflation rates have a cyclical movement and a longterm oscillation about the trend every three years. This implies a different cycle of inflation rates is completed every three years.

Figure 1: Time Plot for Government Revenue, Government Expenditure, Inflation Rates and Investment

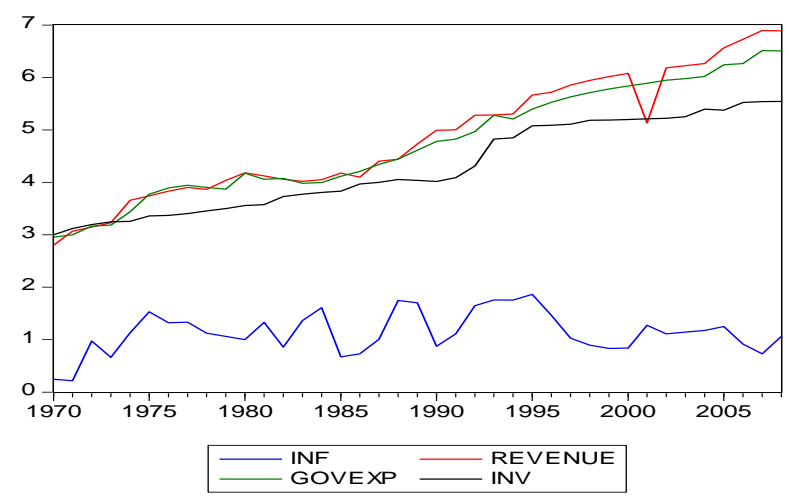

For the results in Table 1, all the macro economic variables tested for stationarity using the Augmented Dickey-Fuller (ADF) test reveals the economic 
variables are stationary at the first order difference except inflation rates that is stationary at the ordinary level I(0). That is, government revenue, government expenditure and investment are stationary at I(1).

Table 1: Unit Root Test Using Augmented Dickey-Fuller (ADF)

\begin{tabular}{|l|c|r|c|}
\hline $\begin{array}{l}\text { Economic } \\
\text { Series }\end{array}$ & $\begin{array}{l}\text { ADF Test } \\
\text { Statistic }\end{array}$ & $\begin{array}{l}\text { At 95\% } \\
\text { Critical } \\
\text { Level }\end{array}$ & $\begin{array}{l}\text { Order of } \\
\text { Integration }\end{array}$ \\
\hline REVENUE & -9.3274 & -2.9434 & $\mathrm{I}(1)$ \\
GOVEXP & -6.6289 & -2.9434 & $\mathrm{I}(1)$ \\
INV & -4.7931 & -2.9434 & $\mathrm{I}(1)$ \\
INF & -4.5341 & -2.9434 & $\mathrm{I}(0)$ \\
\hline
\end{tabular}

Considering Table 2 below, none of the deterministic variable is restricted to the co-integration space. Likelihood ratio is the trace test adjusted for degrees of freedom. The critical values are taken from Osterwald- Lenum (1992). The * indicates rejection of likelihood ratio tests at $5 \%$ and $1 \%$ significance level. Likelihood Ratio test indicates one co-integrating equation at $5 \%$ and $1 \%$ significance level. In determining the number of co-integrating vectors, we used the degrees of freedom, adjusted version of trace statistic. Then, the test statistic strongly rejects the null hypothesis of no co-integration in favour of one co-integration relationship at $5 \%$ and $1 \%$ level of significant.

Table 2: Johansen Co-integration Test

\begin{tabular}{|c|c|c|c|c|c|}
\hline $\begin{array}{l}\text { Hypothesized } \\
\text { No. of CE (s) }\end{array}$ & $\begin{array}{l}\text { Eigen } \\
\text { value }\end{array}$ & $\begin{array}{l}\text { Trace } \\
\text { Statistic }\end{array}$ & $\begin{array}{l}0.05 \\
\text { Critical } \\
\text { Value }\end{array}$ & $\begin{array}{l}0.01 \\
\text { Critical } \\
\text { Value }\end{array}$ & Prob. ${ }^{* \star}$ \\
\hline None $^{*}$ & 0.616775 & 56.94743 & 47.85613 & 54.68150 & 0.0056 \\
\hline At most 1 & 0.406361 & 24.33691 & 29.79707 & 35.45817 & 0.1866 \\
\hline At most 2 & 0.173142 & 6.606430 & 15.49471 & 19.93711 & 0.6238 \\
\hline At most 3 & 0.004176 & 0.142264 & 3.841466 & 6.634897 & 0.7060 \\
\hline
\end{tabular}

Models Estimation for the Government Revenue, Government Expenditure, Inflation Rate and Investment

$$
\begin{aligned}
\mathrm{INF}_{\mathrm{t}} & =0.524590 \\
& {[2.67490] \mathrm{INF}_{\mathrm{t}-1} } \\
& +1.046313 \\
& {[1.42874] } \\
& -0.990330 \\
& {[-1.33618] \mathrm{INV}_{\mathrm{t}-1} }
\end{aligned}
$$

$$
\begin{aligned}
& \text { REVENUE }_{\mathrm{t}} \\
& =\frac{0.584411}{[1.10521]} \text { GOVEXP }_{\mathrm{t}-1}+\varepsilon_{t}
\end{aligned}
$$

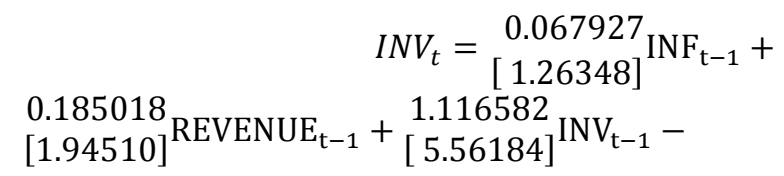$$
\begin{gathered}
0.256013 \\
{[-1.26004]} \\
0.323372 \mathrm{INV}_{\mathrm{t}-2}- \\
{[-1.49094]} \\
\text { GOVEXP }_{\mathrm{t}-1}+{ }^{0.228457}[1.24848]
\end{gathered} \mathrm{GOVEXP}_{\mathrm{t}-2}+\varepsilon_{t}
$$

$$
\begin{aligned}
& \text { GOVEXP }_{\mathrm{t}}={ }_{[1.91962]}^{0.112079} \text { INF }_{\mathrm{t}-1}-\frac{0.057691}{[-1.01693]} \mathrm{INF}_{\mathrm{t}-2} \\
& +{ }_{[1.87368]}^{0.193554} \text { REVENUE }_{\mathrm{t}-1} \\
& +{ }_{[1.55511]}^{0.343143} \mathrm{INV}_{\mathrm{t}-2} \\
& +{ }_{[2.89189]}^{0.681178} \text { GOVEXP }_{\mathrm{t}-1}+\varepsilon_{t}
\end{aligned}
$$

The four models above were obtained for the $V A R$ Model Estimation and the first model shows that current inflation rates is explained and determined by inflation rates in its first previous lag and investment in the first and second previous lags by observing the values of $\mathrm{t}$-statistics in the parenthesis above. The value of $R^{2}(0.863832)$ shows that $(86 \%)$ of variation in the dependent variable is explained by the independent variables and this indicates a good model fit. The second model shows that current revenue is explained and determined by government expenditure in its first previous lag by observing the values of t-statistics in the parenthesis above and the value of $R^{2}(0.970179)$ shows that $(97 \%)$ variation in the dependent variable is explained by the independent variables and the value of adjusted $R^{2}$ squared (0.936229) shows it is good fit. The third model shows that current investment is explained and determined by inflation rates, government revenue, investment and government expenditure in their first previous lags. Investment and government expenditure as well determines the current investment in their second previous lags by observing the values of $\mathrm{t}$-statistics in the parenthesis above and the value of $R^{2}(0.986910)$ shows that $(99 \%)$ variation in the dependent variable is explained by the independent variables and the value of adjusted $R^{2}$ squared $(0.983245)$ shows it is good fit. While the last 
model shows that current government expenditure is explained and determined by inflation rates, government revenue and government expenditure in their first previous lags and inflation rates and investment as well determine current government expenditure in their second previous lag by observing the values of t-statistics in the parenthesis above and the value of $R^{2}(0.988712)$ shows that $(99 \%)$ variation in the dependent variable is explained by the independent variables and the value of adjusted $R^{2}$ squared $(0.983245)$ shows it is good fit.

Using VAR lag order selection criteria, AIC and SBIC criterion functions were both minima at $\operatorname{lag}(1)$ and lag length of order (1) is suggested. Checking for the independent distributed of the residual using Portmanteau test result in table 3 below, the residual passes the white noise test since no autocorrelation is left at $\operatorname{lag}(2)$ and on the basis we select $V A R(2)$ as the specification for analysis. Using the Vector Autoregressive Residual Normality test result in table 4 below, the residuals are jointly normal since the joint Skewness, Kurtosis and Jarque-Bera are significant and this implies that residuals are multivariate normal.

Table 3: Residual Autocorrelation (Portmanteau Test)

\begin{tabular}{|l|c|c|c|c|c|}
\hline Lags & Q-Stat & Prob. & Adj Q-Stat & Prob. & $\mathrm{df}$ \\
\hline 1 & 1.722404 & $\mathrm{NA}^{*}$ & 1.770249 & $\mathrm{NA}^{*}$ & $\mathrm{NA}^{*}$ \\
2 & 12.93350 & $\mathrm{NA}^{*}$ & 13.62198 & $\mathrm{NA}^{*}$ & $\mathrm{NA}^{*}$ \\
3 & 23.47824 & 0.1015 & 25.09713 & 0.0681 & 16 \\
4 & 34.76951 & 0.3374 & 37.75705 & 0.2228 & 32 \\
5 & 43.15339 & 0.6714 & 47.45090 & 0.4952 & 48 \\
6 & 54.71592 & 0.7894 & 61.25134 & 0.5743 & 64 \\
\hline
\end{tabular}

Table 4: Vector Autoregressive Residual Normality Test

\begin{tabular}{|c|l|l|l|l|}
\hline Component & Skewness & $\begin{array}{l}\text { Chi } \\
\text { Square }\end{array}$ & Df & Prob. \\
\hline 1 & 1.246508 & 4.700218 & 1 & 0.0295 \\
2 & 7.302857 & 28.54331 & 1 & 0.0000 \\
3 & 4.529050 & 3.604408 & 1 & 0.0576 \\
4 & 1.479899 & 3.562341 & 1 & 0.0591 \\
\hline Joint & & 40.45028 & 4 & 0.0000 \\
\hline
\end{tabular}

\begin{tabular}{|c|l|l|l|l|}
\hline Component & Kurtosis & $\begin{array}{l}\text { Chi } \\
\text { Square }\end{array}$ & Df & Prob. \\
\hline 1 & 0.002944 & $5.34 \mathrm{E}-05$ & 1 & 0.9942 \\
2 & -1.592587 & 15.64073 & 1 & 0.0001 \\
3 & 1.093147 & 7.368990 & 1 & 0.0066 \\
4 & 0.277066 & 0.473387 & 1 & 0.4914 \\
\hline Joint & & 23.48316 & 4 & 0.0001 \\
\hline
\end{tabular}

\begin{tabular}{|c|c|c|c|}
\hline Component & Jarque-Bera & df & Prob. \\
\hline 1 & 4.740271 & 2 & 0.9942 \\
\hline 2 & 44.18404 & 2 & 0.0001 \\
\hline 3 & 10.97340 & 2 & 0.0066 \\
\hline 4 & 4.035728 & 2 & 0.4914 \\
\hline Joint & 63.93344 & 8 & 0.0000 \\
\hline
\end{tabular}

Time Series Regression Analysis: Below are the results obtained from the time series regression with lag explanatory variables analysis.

Regressing the current inflation rates on the present and two past lags of government revenue, government expenditure and investment yields the result in the above table. It can be observed that all $p$-values are greater than 0.05 and this implies that the present and two past lags of government revenue, government expenditure and investment do not explain and determine the present inflation 
Table 5. Dependent Variable (Inflation Rates)

\begin{tabular}{|l|l|l|l|l|}
\hline Variable & coefficient & Std.Error & t-Stat. & Prob. \\
\hline \hline C(1) & 0.897943 & 0.685980 & 1.308992 & 0.2016 \\
C(2) & 0.500036 & 0.804837 & 0.621288 & 0.5396 \\
C(3) & -0.016037 & 0.688471 & -0.023294 & 0.9816 \\
C(4) & 0.792587 & 0.546545 & 1.450178 & 0.1585 \\
C(5) & 0.569595 & 0.935276 & 0.609013 & 0.5476 \\
C(6) & -1.235846 & 0.825049 & -1.497908 & 0.1458 \\
C(7) & -0.198777 & 0.328755 & -0.604637 & 0.5505 \\
C(8) & -0.524207 & 0.335373 & -1.563057 & 0.1297 \\
C(9) & -0.578896 & 0.360708 & -1.604886 & 0.1202 \\
\hline
\end{tabular}

$\mathrm{INF}=C(1)^{*}$ GOVEXP(1)+C(2)*GOVEXP(-1)+

$C(3)^{*} G O V E X P(-2)+C(4)^{*} I N V(1)+$ $C(5)^{*} I N V(-1)+C(6)^{*} I N V(-2)+$

$C(7)^{*} R E V E N U E(1)+R E V E N U E(-1)+$ $C(9)^{*} R E V E N U E(-2)$

The value of $R^{2}$ (0.819469) shows that $(81 \%)$ variation in the dependent variable is explained by the explanatory variables and this show a weak predictive power. The value of Durblin-Waston statistic (1.530050) shows no evidence of serial correlation in the residual as DW statistic is around 2.

Table 6. Dependent Variable (Government Revenue)

\begin{tabular}{|l|l|l|l|l|}
\hline Variable & coefficient & Std.Error & t-Stat. & Prob. \\
\hline \hline C(1) & -0.164132 & 0.101366 & -1.619205 & 0.1170 \\
C(2) & -0.005962 & 0.108636 & -0.054882 & 0.9566 \\
C(3) & 0.073874 & 0.107186 & 0.689216 & 0.4966 \\
C(4) & 1.084415 & 0.294349 & 3.684119 & 0.0010 \\
C(5) & -0.140490 & 0.429525 & -0.327082 & 0.7461 \\
C(6) & 0.365418 & 0.351453 & 1.039735 & 0.3077 \\
$C(7)$ & 0.020336 & 0.320819 & 0.063387 & 0.9499 \\
$C(8)$ & 0.075746 & 0.505768 & 0.149765 & 0.8821 \\
$C(9)$ & -0.409990 & 0.438081 & -0.935878 & 0.3576 \\
\hline
\end{tabular}

REVENUE $=C(1)^{*} I N F(1)+C(2)^{*} I N F(-1)+$ $C(3)^{*} I N F(-2)+C(4)^{*}$ GOVEXP(1) + $C(5)^{*} \operatorname{GOVEXP}(-1)+$

$C(6)^{*} G O V E X P(-2)+C(7)^{*} I N V(1)+I N V(-1)+$ $C(9)^{*} \operatorname{INV}(-2)$
Regressing the current government revenue on the present and two past lags of inflation rates, government expenditure and investment yields the result in the above table. It can be observed from the $p$-values that government expenditure in its present lag explains and determines the present government revenue.

The value of $R^{2}(0.971248)$ shows that $(97 \%)$ variation in the dependent variable is explained by the explanatory variables. The value of DurblinWaston statistic (2.441740) shows no evidence of serial correlation in the residual as DW statistic is around 2.

Table 7. Dependent Variable (Investment

\begin{tabular}{|l|l|l|l|l|}
\hline Variable & coefficient & Std.Error & t-Stat. & Prob. \\
\hline \hline $\mathrm{C}(1)$ & -0.164132 & 0.101366 & -1.619205 & 0.1170 \\
$\mathrm{C}(2)$ & -0.005962 & 0.108636 & -0.054882 & 0.9566 \\
$\mathrm{C}(3)$ & 0.073874 & 0.107186 & 0.689216 & 0.4966 \\
$\mathrm{C}(4)$ & 1.084415 & 0.294349 & 3.684119 & 0.0010 \\
$\mathrm{C}(5)$ & -0.140490 & 0.429525 & -0.327082 & 0.7461 \\
$\mathrm{C}(6)$ & 0.365418 & 0.351453 & 1.039735 & 0.3077 \\
$\mathrm{C}(7)$ & 0.020336 & 0.320819 & 0.063387 & 0.9499 \\
$\mathrm{C}(8)$ & 0.075746 & 0.505768 & 0.149765 & 0.8821 \\
$\mathrm{C}(9)$ & -0.409990 & 0.438081 & -0.935878 & 0.3576 \\
\hline
\end{tabular}

$I N V=C(1)^{*} I N F(1)+C(2)^{*} I N F(-1)+$

$C(3)^{*} \operatorname{INF}(-2)+C(4)^{*} G O V E X P(1)+$ $C(5)^{*} G O V E X P(-1)+C(6)^{*} G O V E X P(-2)+$

$C(7)^{*} R E V E N U E(1)+\quad R E V E N U E(-1)+$ $C(9)^{*} R E V E N U E(-2)$

Regressing the current investment on the present and two past lags of government revenue, inflation rates and government expenditure yields the result in the above table. It can be observed from the p-values that government expenditure in its present lag explains and determines the present investment.

The value of $R^{2} \quad(0.963713)$ shows that (96\%) variation in the dependent variable is explained by the explanatory variables. The value of DurblinWaston statistic $(0.628702)$ shows there is evidence of serial correlation in the residual. 
Table 8. Dependent Variable (Government Expenditure)

\begin{tabular}{|l|l|l|l|l|}
\hline Variable & coefficient & Std.Error & t-Stat. & Prob. \\
\hline \hline $\mathrm{C}(1)$ & 0.102465 & 0.053766 & 1.905757 & 0.0674 \\
$\mathrm{C}(2)$ & 0.088354 & 0.057142 & 1.546199 & 0.1337 \\
$\mathrm{C}(3)$ & -0.050658 & 0.055863 & -0.906823 & 0.3725 \\
$\mathrm{C}(4)$ & 0.025144 & 0.157879 & 0.159264 & 0.8746 \\
$\mathrm{C}(5)$ & -0.149496 & 0.245917 & -0.607914 & 0.5483 \\
$\mathrm{C}(6)$ & 0.440922 & 0.197729 & 2.229933 & 0.0343 \\
$\mathrm{C}(7)$ & 0.163366 & 0.073477 & 2.223354 & 0.0348 \\
$\mathrm{C}(8)$ & 0.328619 & 0.086459 & 3.800883 & 0.0007 \\
$\mathrm{C}(9)$ & 0.195908 & 0.077670 & 2.522299 & 0.0179 \\
\hline
\end{tabular}

GOVEXP $=C(1)^{*} I N F(1)+C(2)^{*} I N F(-1)+$

$C(3)^{*} I N F(-2)+C(4)^{*} I N V(1)+$

$C(5)^{*} I N V(-1)+C(6)^{*} I N V(-2)+$

$C(7)^{*} \operatorname{REVENUE}(1)+\operatorname{REVENUE}(-1)+$

$$
C(9)^{*} R E V E N U E(-2)
$$

Regressing the current government expenditure on the present and two past lags of government revenue, inflation rates and investment yields the result in the above table. It can be observed from the $\mathrm{p}$-values that investment in its second previous lag and government revenue in its present and two past lags explain and determine the present government expenditure.

The value of $R^{2}(0.97248)$ shows that $(97 \%)$ variation in the dependent variable is explained by the explanatory variables. The value of Durblin-Waston statistic (2.144710) shows no evidence of serial correlation in the residual as DW statistic is around 2
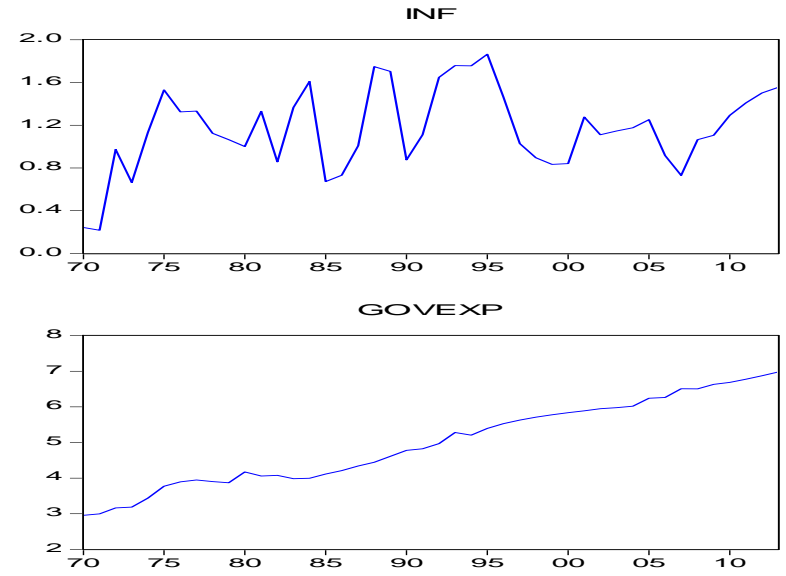

Vector Autoregressive and Time Series Regression Comparism: Using $R^{2}$ to compare the level of variation explained by the series consider as independent variables in $V A R$ and Time Series Regression models estimation, it is shown that the variation explained in $V A R$ models were slightly higher than the Time Series Regression models. This indicates that the VAR models establish a better inter-relationship among the macro-economic series.

Foresting with VAR AND Time Series Regression Models: Vector autoregressive and time series regression models obtained is used to forecast out sample values for all the economic series and static forecast will be used.

Table 9. Forecasting Results Using Vector Autoregressive Models

\begin{tabular}{|l|l|l|l|l|}
\hline Year(s) & $\begin{array}{l}\text { Government } \\
\text { Revenue in } \\
\text { Billion(s) } \\
\text { naira }\end{array}$ & $\begin{array}{l}\text { Government } \\
\text { Expenditure } \\
\text { in Billion(s) } \\
\text { naira }\end{array}$ & $\begin{array}{l}\text { Inflation } \\
\text { Rates in } \\
(\%)\end{array}$ & $\begin{array}{l}\text { Investment } \\
\text { in Billion(s) } \\
\text { naira }\end{array}$ \\
\hline 2009 & 6.881106 & 6.633381 & 1.105948 & 5.688482 \\
2010 & 6.920296 & 6.687671 & 1.293117 & 5.798896 \\
2011 & 6.999770 & 6.777695 & 1.409578 & 5.925796 \\
2012 & 7.087328 & 6.873394 & 1.502065 & 6.045665 \\
2013 & 7.190662 & 6.980018 & 1.555559 & 6.162683 \\
\hline
\end{tabular}

The table above shows forecasting results for government revenue, government expenditure, inflation rates and investment from 2009 - 2013. The forecasting results show that all the economic series are increasing steadily except Inflation rates that are increasing rapidly each year.
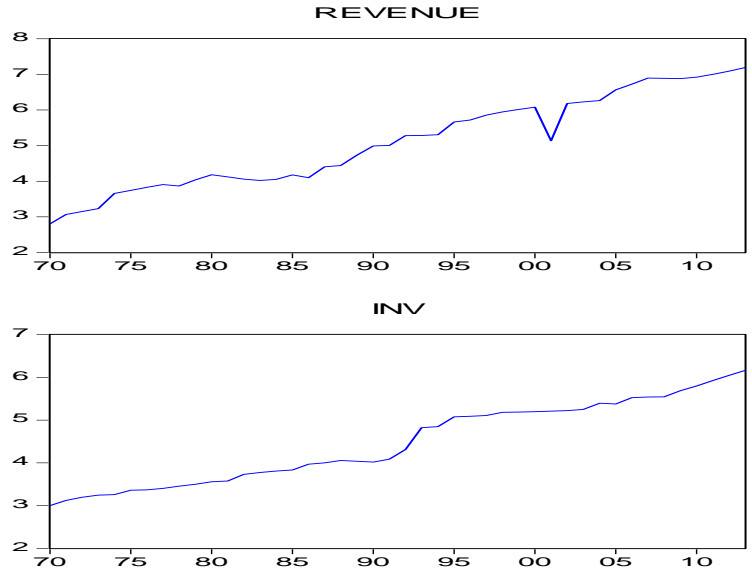

Fig 2. Forecast Graphs Using VAR Models 
Table 10. Forecasting Results Using Time Series Regression Models

\begin{tabular}{|l|l|l|l|l|}
\hline Year(s) & $\begin{array}{l}\text { Government } \\
\text { Revenue in } \\
\text { Billion(s) } \\
\text { naira }\end{array}$ & $\begin{array}{l}\text { Government } \\
\text { Expenditure } \\
\text { in Billion(s) } \\
\text { naira }\end{array}$ & $\begin{array}{l}\text { Inflation } \\
\text { Rates in } \\
(\%)\end{array}$ & $\begin{array}{l}\text { Investment } \\
\text { in Billion(s) } \\
\text { naira }\end{array}$ \\
\hline 2009 & 6.845705 & 6.633381 & 1.068430 & 5.801822 \\
2010 & 6.939273 & 6.687671 & 1.380202 & 5.873002 \\
2011 & 7.013139 & 6.777695 & 1.440577 & 6.006178 \\
2012 & 7.104153 & 6.873394 & 1.525205 & 6.101037 \\
2013 & 7.110052 & 6.980018 & 1.531105 & 6.110021 \\
\hline
\end{tabular}
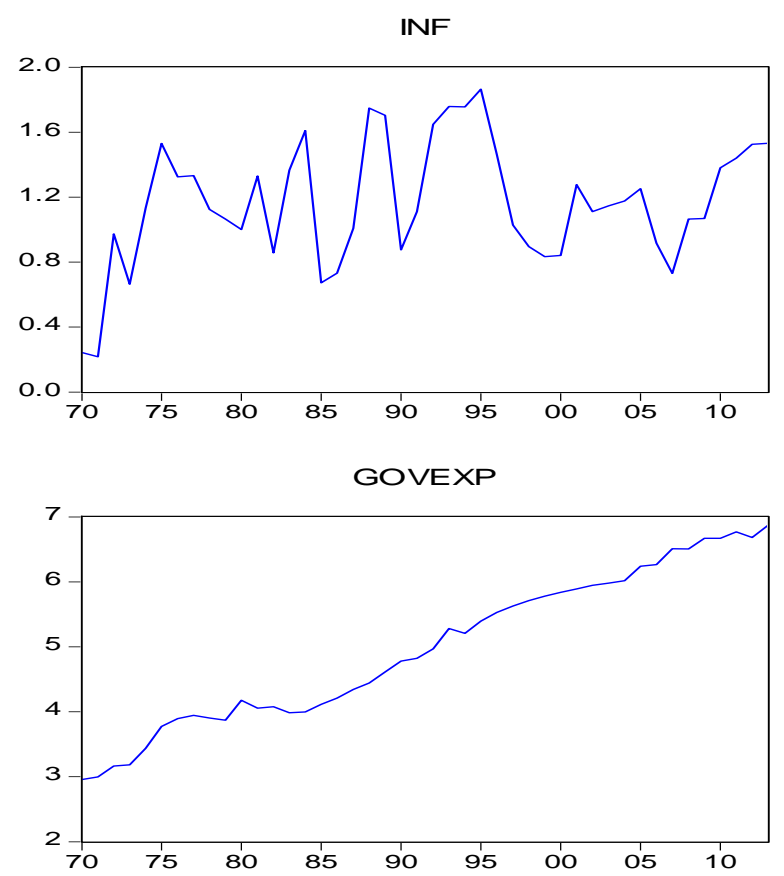

The table above shows forecasting results for government revenue, government expenditure, inflation and investment from 2009 - 2013. The forecasting results show that all the economic series are increasing steadily except Inflation rates that are increasing rapidly each year.

Forecast Performance: The forecast performance of the two models will be determined by comparing the forecast evaluation result in table 11

\section{Fig 3. Forecast Graphs Using Time Series Regression Models}

The results of using VAR models to forecast inflation rates, government revenue, government expenditure and investment for the annul period of $2009-2013$ used for comparison is not intended as a formal model evaluation but simply as a demonstration that the nature of VAR model can have important implications for forecast performance. The alternative model considered is time series regression model and this model is very useful as well.
The forecast performance results above shows that using vector autoregressive is better than time series regression for forecasting accurate values for inflation rates, government revenue, government expenditure and investment, since all the values of the forecast evaluations for vector autoregressive models are less than that of time series regression models. 
Am. J. Sci. Ind. Res., 2013, 4(1): 49-58

Table 11. Forecast Evaluation (2009 - 2013)

\begin{tabular}{|l|l|l|}
\hline Inflation & Vector Autoregressive & Time Series Regression \\
\hline Root Mean Square Error & 0.291060 & 0.302457 \\
Mean Absolute Error & 0.232815 & 0.248473 \\
Theil Inequality Coef. & 0.110752 & 0.123405 \\
Bias Proportion & 0.003779 & 0.005437 \\
Variance Proportion & 0.003779 & 0.087037 \\
\hline
\end{tabular}

\begin{tabular}{|l|l|l|}
\hline Government Revenue & Vector Autoregressive & Time Series Regression \\
\hline Root Mean Square Error & 0.172531 & 0.172975 \\
Mean Absolute Error & 0.106115 & 0.106448 \\
Theil Inequality Coef. & 0.016037 & 0.016355 \\
Bias Proportion & 0.000626 & 0.002305 \\
Variance Proportion & 0.030822 & 0.052282 \\
\hline
\end{tabular}

\begin{tabular}{|l|l|l|}
\hline Investment & Vector Autoregressive & Time Series Regression \\
\hline Root Mean Square Error & 0.087303 & 0.148090 \\
Mean Absolute Error & 0.063060 & 0.115486 \\
Theil Inequality Coef. & 0.009407 & 0.016131 \\
Bias Proportion & 0.002347 & 0.018518 \\
Variance Proportion & 0.035894 & 0.038640 \\
\hline
\end{tabular}

\begin{tabular}{|l|l|l|}
\hline Government Expenditure & Vector Autoregressive & Time Series Regression \\
\hline Root Mean Square Error & 0.080538 & 0.093224 \\
Mean Absolute Error & 0.063062 & 0.076598 \\
Theil Inequality Coef. & 0.007824 & 0.009038 \\
Bias Proportion & 0.000002 & 0.011257 \\
Variance Proportion & 0.002746 & 0.007626 \\
\hline
\end{tabular}

\section{CONCLUSION}

The time plots showed that each year there is a simultaneously increase in the values of government revenue, government expenditure and investment except a sharp downward shift in government revenue in 2001. While inflation fluctuate from year to year, cyclical in movement and a cycle is completed every three years. The Augmented Dickey Fuller tests shows that other series are stationary at the first differencing, I(1) and only inflation rates is stationary at the ordinary level, I(0). The Johansen cointegration test shows that there is at least one cointegrated series out of four economic series at $5 \%$ and $1 \%$.

Vector Autoregressive and Time Series Regression models shows that there exist inter-relationship among all the macroeconomic variables but the relationship were better shown using VAR models.

The forecast from the vector autoregressive and time series regression models shows that there is a 
steady increase in the values of all the macro economic variables except inflation rates with sharp increase for the five years forecasted. While using the forecast performance, vector autoregressive models is better than the time series regression models since the forecast evaluation from the vector autoregressive models is less than that of time series regression models.

\section{REFERENCES}

Aaker, D., James C. and Robert J. (1982), "Modeling Advertising-Sales relationships involving feedback: A Time series analysis of six cereal brands," Journal of Marketing Research, 19 (February), 116-125

Adams, Arthur and Mark Moriarty (1981), " The advertisingsales relationship: Insights from Transfer-function modeling," Journal of Advertising Research, 21 (June), 41-46.

Adebiyi, M. A. (2005). "Financial Sector Reform and Monetary Policy Shocks in Nigeria," A Vector Autoregressive Model. Ph.D. Thesis, University of Lagos, Lagos.

Ajibade, O.A. "Econometric Analysis of some Economic Indicators using Simultaneous Equations," An Unpublished M.Sc. Thesis, University of Ibadan.

Ashley, R., Clive Granger and Richard Schmalensee (1980), "Advertising and Aggregate Consumption: An analysis of causality,E" conometrica, 48 (July), 11491167.

Blanchard, O. J. and Fischer, .S (1990) "Lectures on Macroeconomic" M. I. T Press Cambridge M.A.

Box, George E. P. and Gwilym M. Jenkins (1976). Time Series Analysis: Forecasting and Control, Revised Edition, Oakland, CA: Holden-Day.

Brischetto, A. \& Voss, G. (1999). "Structural Vector Autoregression Model of Monetary Policy in Australia," Research Discussion Paper, Reserve Bank of Australia, 11.

Chattfield, C. ((1975): "The Analysis of Time Series". An introduction, New York, Chapman and Hall.

Dickey, D. A. and Fuller, W. A. (1979). "Distribution of the Estimators for Statistical, Autoregressive Time Series with a Unit Root," Journal of the American 74: $427-431$
Engle, R. F. and Granger, C. W. J. (1987). "Co-integration and Error Correction: Representation, Estimation and Testing," Econometrica, 55: 251 - 276.

Gregory, C. Reinsel and Sung, R. Ahn. (1992). "Vector Autoregressive Models with Unit Root and Reduced Rank Structure: Estimation, Likelihood Ratio Test and Forecasting." Journal of Time Series Analysis, Vol. 13 page $353-375$.

Micheal, P. Clements and Hans-matrin, Krolzig. (1997) "A Comparison of the Forecast Performance of Markovswitching and Threshold Models of US GNP." Econometric Journal.

Hamilton, J. D. (1994) "Time Series Analysis," Princeton University Press, Princeton, New Jersey.

Johanson, S. (1995)."Likelihood-based Inference in Cointegrated Vector Autoregressive Models," Oxford University Press.

Johnston and DiNardo (1997), Econometric Methods, 4th Edition.

Lütkepohl, Helmut (2005). "New Introduction to Multiple Time Series Analysis," $2^{\text {st }}$ Edition Pp. 1 - 191.

Lutkepohl, H. (1991). Introduction to Multiple Time Series Analysis. Springer-Verlag, Berlin.

Lütkepohl, Helmut (1999). New Introduction to Multiple Time Series Analysis.

Reinsel, G. C. \& Ahn, S. K. (1992). Vector autoregressive models with unit roots and reduced rank structure: Estimation, likelihood ratio test, and forecasting, Journal of Time Series Analysis 13: 353-375.

Osterwald-Lenum, Michael (1992). "A Note with Quantiles of the Asymptotic Distribution of the Maximum Likelihood Cointegration Rank Test Statistics," Oxford Bulletin of Economics and Statistics, 54, 461-472.

Pfaff, B (2004): urca "Unit root and Co integration Test for Time Series" R package, version 0.6-1.

Rao, B.B (1994): "Co integration for Applied Economists" The Macmillan Press Ltd. London, UK.

Sims, C.A. (1980) "Macroeconomics and Reality," Econometrica.

Watson, M. (1994). "Vector Autoregressions and Cointegration," in Handbook of Econometrics, Volume IV. R.F. Engle and D. McFadden (eds.). Elsevier Science Ltd., Amsterdam 